Revista de la red interuniversitaria de estudios sobre las literaturas rioplatenses contemporáneas en Francia

\title{
“¿Independientes de qué ?" : una entrevista a Damián Tabarovsky
}

Martín Arias y Enrique Schmukler

\section{OpenEdition}

\section{Journals}

Edición electrónica

URL: http://journals.openedition.org/lirico/2046

DOI: $10.4000 /$ lirico.2046

ISSN: 2262-8339

Editor

Réseau interuniversitaire d'étude des littératures contemporaines du Río de la Plata

Referencia electrónica

Martín Arias y Enrique Schmukler, " "¿Independientes de qué ?" : una entrevista a Damián Tabarovsky », Cuadernos LIRICO [En línea], 13 | 2015, Puesto en línea el 15 diciembre 2015, consultado el 05 mayo 2019. URL : http://journals.openedition.org/lirico/2046 ; DOI : 10.4000/lirico.2046

Este documento fue generado automáticamente el 5 mayo 2019.

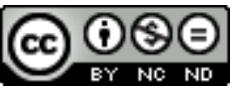

Cuadernos LIRICO está distribuido bajo una Licencia Creative Commons Atribución-NoComercialSinDerivar 4.0 Internacional. 


\title{
“independientes de qué ?” : una entrevista a Damián Tabarovsky
}

\author{
Martín Arias y Enrique Schmukler
}

hay algo muy original en tus columnas dominicales del diario perfil, Que tiene QUe Ver con el modo en QUe en ellas aparece algo QUe, a falta de Un nombre MEJOR, PODRÍAMOS lLAMAR "CrítiCA EDITORIAL". ES DECIR, AL COMENTAR LIBROS DESDE UNA PERSPECTIVA LITERARIA, INSISTís MUCHO EN EL gesto EDITORIAL QUE LOS HACE

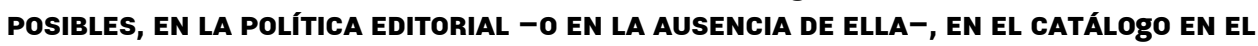
CuAl Se inserta tal Libro, en EL hecho de QUe no Se edite tal otro, etc. ¿ cómo SURgE EN VOS ESTA MANERA DE LEER ?

Dejando de lado que no puede haber nada "original" en mis columnas en el diario Perfil, precisamente por estar publicadas en un diario (el periodismo en todo se opone a la originalidad), y que la pregunta acerca de "cómo surge" mi manera de leer no viene al caso aquí -suspendamos cualquier tentación autobiográfica o autorreferente- podría responder, sí, que en esos artículos de ocasión me interesa introducir una reflexión que incluye a la lectura, es decir, a la lectura que genera escritura (aunque sea "dominical"), y al modo en que esa lectura vincula textos con libros. ¿Qué leemos? ¿En qué instancias se leen textos, y en cuáles libros? (es decir, textos envueltos en tapas y contratapas, distribuidos en librerías u otros "puntos de venta", con PVP, que integran un catálogo, etc., etc.). Mi idea es darle visibilidad a esa fricción, a esos dos sistemas de lectura y de circulación. Me parece que la institución editorial es un formidable campo de tensiones -ideológicas, económicas, estéticas- no suficientemente estudiado. $\mathrm{O}$ en todo caso, cuando lo fue, muchas veces encontré insatisfactorio ese abordaje (recuerdo que en los ' 80 y '90 aparecieron varias lecturas académicas - tesis y esas cosas- sobre historia de las revistas culturales argentinas, marcadas por un uso abusivo de Bourdieu, que me resultaron empobrecedoras).

Lo mío, como es evidente, no tiene demasiadas pretensiones, pero con esas limitaciones "dominicales", propongo retomar la tensión entre texto y libro, que no es otra que la tensión entre escritura y mercado, tema sobre sobre el que siempre vuelvo. 
EN UNA DE ESAS COLUMNAS, “EL EDITOR Y SU LIBRo”, DE OCTUBRE DE 2011, INVENTASTE UN

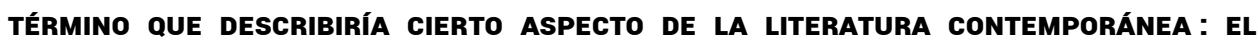
"EDITOR-REY". SE TRATARÍA DE UNA CONCEPCIÓN DE LA LITERATURA EN LA QUE LE EDITOR HA gaNAdO EL CENTRO DE LA ESCENA LITERARIA, OPACANDO, INCLUSO, A LA figURA DEL ESCRITOR. ¿ PODRÍAS DESARROLLAR UN POCO MÁs ESTA IDEA ? ¿QUÉ TIPO DE REFLEXIÓN HACÉS SOBRE LA RELACIÓN ENTRE EDITORES Y AUTORES EN LA ACTUALIDAd DE LA LITERATURA ARgENTINA?

Creo que hay un doble fenómeno, quizás concomitante, o que funciona en sincronía. De un lado, debido al brutal proceso de concentración editorial -que arranca en los '90 y que aún no ha concluido : el editorial es uno de los mercados en los que aún pervive un neoliberalismo triunfante- la figura del editor ha sido reemplazada por la alianza entre gerentes de marketing y agentes literarios.

Del otro, del lado de las editoriales "prestigiosas" (palabra de la que huyo como de la peste), en muchas de ellas - sobre todo europeas- se impone la figura del "gran editor" que supone que el catálogo de su editorial es "su obra", y que cada libro editado es un capítulo de una gran novela, que vendría a ser el fondo editorial. En este segundo escenario es que reparo críticamente en la figura del "Editor Rey" que, igual que los productores con los músicos y los curadores con las artistas, también se imagina más importante que los escritores. Un sinfín de editoriales llamadas con infinita inmodestia “independientes" - de Argentina a México pasando por España-creadas en la última década o década y media, reproducen este error.

Yo sigo pensando al editor como un personaje oscuro, un poco fracasado, algo nerd, mucho menos meritorio que un escritor. No sé en qué momento se volvió cool ser editor de una pequeña editorial. En los 80 , los hijos de los ministros alfonsinistas armaban bandas de rock, pero ya en los 90 los hijos de los ministros menemistas abrieron editoriales de poesía... Recuerdo a Héctor Libertella, genial escritor ( $j$ el mejor de todos ! ) y ex editor en Fondo de Cultura Económica, Monte Ávila y varias empresas más, diciendo: "un editor es alguien que tiene una calculadora sobre su escritorio". Ahí reside parte de la verdad de este oficio.

Tal vez debamos pensar la época bajo la preeminencia de la industria cultural para comprender lo que ocurre. La industria cultural es la gran enemiga del arte. Reemplaza al valor, a la crítica, por la sociología (la sociología no juzga: los fenómenos simplemente le parecen "interesantes", "significativos”). La sociología no democratiza : aplana, achata, enumera ; vuelve todo número, quantum. Que los gobiernos progresistas, aquí o allá, lo primero que creen es una Secretaria de Industrias Culturales, no es más que un signo anticipado de su fracaso. La industria cultural propone a la figura del entrepreneur, del gerente de contenidos como emblema de la época.

Volviendo entonces al comienzo de la respuesta : al mismo tiempo que, por un lado, en los grandes holdings desaparece la figura del editor, esa estampa resurge en toda clase de editoriales pequeñas y medianas, chicas y más chicas, autodenominadas independientes. Independiente, por definición, es un término relacional. Se es independiente de algo, de alguien. ¿Independientes de quién o de qué son las editoriales independientes? Obviamente son independientes en el sentido de que no pertenecen a ningún gran holding. Pero eso no las vuelve necesariamente más dignas. ¿Se dirá entonces que son independientes, porque expresan cierta independencia de criterio ? ¿ Que el criterio con el que evalúan un manuscrito (i palabra bien anticuada !) no está marcado por el clima de época, por las concesiones al mercado ? Si miramos de 
cerca sus catálogos, veremos que -aquí, en el resto de América Latina, en todas partes - está lleno de editoriales independientes con catálogos espantosos. Y que, a la inversa, aún en crisis, hay zonas de las grandes editoriales que todavía publican buena literatura, o por lo menos eso ocurría hasta hace menos de un lustro. El catálogo de literatura argentina de la Sudamericana de los 90, la de Chitarroni -salvo obviamente Soriano- era muy radical. Hace pocos años, el del sello Caballo de Troya, en España, perteneciente al grupo entonces llamado Random-House/Mondadori, a cargo de Constantino Bértolo, también.

Entre tanto, en las editoriales independientes se creó un nuevo monstruo : el "Editor Rey". El que supone que el catálogo es su obra. Pues : los editores no tienen obra. Obra tienen los autores. Y si el postestructuralismo francés deconstruyó -con elegancia, erudición y violencia- la propia noción de autor (y por lo tanto la de obra) en el mismo horizonte epistemológico con el que cuestionó el concepto de hombre y, más aún, de sujeto; es decir, en un movimiento donde el autor era reemplazado, o mejor dicho, disuelto en otra categoría -en una categoría llamada "texto"-, evidentemente ese esfuerzo descomunal, vanguardista y tan cercano a mí ; ese esfuerzo, digo, esa batalla por sospechar del autor, fue en vano. Fue derrotada. Todos estos años de socialdemocracia (neo) liberal dieron como resultado, entre muchos otros aspectos, una vuelta al sujeto, y de allí al autor, al auge de la biografía como género comercial ( $i$ a quién le importa la vida de escritor?) y de allí, otro paso, a la figura del editor independiente, al "Editor Rey".

Los grandes holdings multinacionales son impensables sin el neoliberalismo. El auge de la edición independiente, también.

\section{¿ POdRÍAs MENCIONAR LOS CRITERIOS ESTÉticos QUe gUían LAS DECISIONES EDITORIALES EN MARdULCe? ¿Cómo SE RELACIONAN ESOS CRITERIOS CON TU PROPIA ESCRITURA LITERARIA ?}

Un criterio, sencillo, es el siguiente : son libros que yo compraría si los publicara otra editorial.

Fuera de eso, no creo que la edición sea "la continuidad de mi escritura por otros medios", sino más bien una forma subrepticia de opinar sobre el estado de la cultura y la literatura contemporánea. Esa "opinión" siempre es elusiva, lateral, levemente descentrada. Busco modos de la sintaxis que recorran caminos alejados del centro, que desconfíen de sí mismos, que pongan en cuestión la prosa cristalizada de la novela convencional, la doxa cotidiana, el habla de los medios de comunicación y la fraseología de la política.

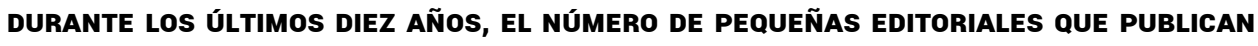
LiterATURA HA AUMENTADO CONSIDERABLEMENTE. A TU JUICIO, ¿ DE QUÉ MOdO INFLUYE ESA PROLIFERACIÓN EDITORIAL EN LA ESCRITURA CONTEMPORÁNEA?

Me gusta mucho el uso que hacen en la pregunta de la palabra "proliferación". Me permití derivarme al María Moliner, y veo que por un lado implica "multiplicarse en abundancia", y de otro "reproducirse en formas similares". Si la edición a cargo de las pequeñas editoriales dio como resultado esos efectos, entonces hay que repensarla críticamente, de un modo urgente. La idea de que existan "formas similares" atenta contra el concepto base de la literatura, a saber, el hecho de ser una suma infinita de experiencias singulares. Dicho de otro modo, como paradoja: ser la similitud de la singularidad. 
¿ Hay ya un modo indie de escribir ficción? No lo sé, pero no lo descarto. A la inversa, sí sé que existe un modo Planeta de escribir. Es una pregunta muy relevante la de saber si "nosotros" nos estamos convirtiendo en mainstream. Pero esa pregunta no debe ocultar que hay catástrofes mayores, como ganar el Premio Planeta, por ejemplo.

¿Cómo Ves El Estado actual de La tRaducción literaria en ARgentina, en PARTICULAR EN LAS PEQUEÑAS EDITORIALES?

Las editoriales pequeñas son casi las únicas casas que traducen hoy en Argentina. Sumadas, traducen en Argentina mucho más que las grandes editoriales multinacionales que, en regla general, importan o imprimen localmente traducciones contratadas y realizadas por sus casas matrices en Barcelona. Sin contar la importancia crucial, desde el punto de vista cultural, de que son traducciones realizadas al castellano de Argentina. Como es sabido, los libros traducidos al castellano en las grandes editoriales multinacionales lo son en España, en el español de España. Allí se toman dos decisiones cruciales : la decisión de qué autores se traducen (y cuáles no) y la lengua con la que se encara la traducción. Luego, envían (como objeto físico o en PDF para imprimir) el libro a cada sucursal de Latinoamérica. Es decir, que si las editoriales pequeñas argentinas no existieran, no habría prácticamente más traducciones hechas en el país. Se perdería entonces riqueza lingüística y diversidad bibliográfica. Estas pequeñas editoriales aseguran en conjunto una masa de libros que si no existiese obligaría a los lectores argentinos a leer solo en el español de España, pero ya no en su inflexión rioplatense. Sin el Estado (prácticamente ausente en temas de apoyo a la edición) estas editoriales cumplen también una función política. Aseguran un debate sobre el estatuto del castellano que hablamos en cada región, debate que proviene del origen de la formación de los estados nacionales. Es una discusión de una actualidad e importancia nodal, que cruza la lengua con la economía, la estética con la política.

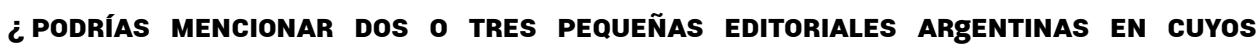
CATÁlogos encuentres afinidades Con tU PROPIA PRÁctica literaria, tanto de ESCRITOR COMO DE EDITOR ? ¿ EN QUÉ SE BASAN ESAS AFINIDADES ?

¿Por qué solo argentinas? Pienso también en varias de las pequeñas editoriales españolas, en zonas de sus catálogos que me interesan: la zona de libros de dominio público de Periférica, la de literatura alemana de Errata Naturae, en la tradición libertaria que repiensa Tumbona de México, en algunas de las apuestas de Hueders, de Chile, en la colección de ensayo literario de escritores de la UDP, también de Chile.

Ya en Argentina, la coherencia del catálogo de ensayo de Eterna Cadencia no me es indiferente, la posibilidad de trabajar con la tradición anglosajona "menor" de La Bestia Equilátera también me resulta estimulante, el trabajo conjunto que Beatriz Viterbo Editora realizó con un autor -César Aira- durante casi veinte años es todo un modelo a seguir.

EN UNA de tUS Últimas COLUMNAS, LUEgO de RECORdAR LA EXPERIENCIA DE ROBERTO

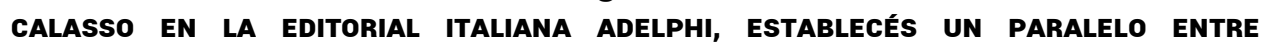
“HORIZONTES POLÍTICOS” Y DECISIONES EDITORIALES. EN EL CONTEXTO DE RADICALIZACIÓN POLÍtica de LOS SETENTA - DECís-, LA LITERATURA ERA OBJETO de UNA desconfianza Que, en términos editoriales, se traducía en UN PRIVilegio del ensayo, PARTicularmente de las ciencias sociales, por sobre la narrativa. ¿ Cómo ENCARAN ESA RELACIÓN EN LA EXPERIENCIA CONCRETA DE LA EDITORIAL MARDULCE ?

Pienso a Marduce como una editorial que indaga críticamente acerca del estatuto de lo contemporáneo. Ahora bien, lo contemporáneo, lo actual, no es algo plano, unívoco, 
homogéneo, sino que opera por pliegues donde se cuela también cierto anacronismo (en esto, soy deudor del Nietzche leído por Agamben). Volver contemporáneo lo anacrónico es parte central de nuestro trabajo y de nuestro catálogo : defendemos el ensayo literario, es decir, libros que hablan sobre otros libros, en un tiempo en el que la publicidad indica que el libro está a punto de desaparecer.

Y también nos seduce una narrativa de la negatividad, novelas que cuestionen la sintaxis hegemónica, que pongan en cuestión los modos oficiales de contar historias. Sospechamos furiosamente del exceso de presente, de la tentación de caer en un nuevo costumbrismo, un costumbrismo posmoderno, por decirlo de algún modo.

Nos gusta pensar que nuestro lector tiene a sus espaldas una gran biblioteca, o que, siendo aún joven, va en camino de tenerla.

Y nos gusta pensar también que la biblioteca no es solo un soporte pequeño burgués, sino un trampolín de nuevas rebeldías y desacuerdos con los poderes del presente.

Mardulce, como otras editoriales amigas, se pregunta entonces si es posible conciliar la dimensión hedonista de la lectura -el placer del texto- con una radicalidad crítica. 